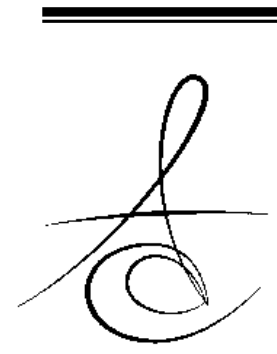

\title{
DOĞU ANADOLU BÖLGESİNDE TEMPOROMANDİBULER EKLEM DİSFONKSIYYONUNUN GÖRÜLME SIKLIĞININ VE FARKINDALIĞININ İNCELENMESİ
}

\section{INVESTIGATION OF THE FREQUENCY AND AWARENESS OF THE TEMPOROMANDIBULAR JOINT DYSFUNCTION IN THE EASTERN ANATOLIA REGION}

\section{öz}

Amaç: Bu araştırmanın amacı, Doğu Anadolu Bölgesinden kliniğimize temporomandibular eklem (TME) rahatsıllığı nedeniyle başvuran hastaları yaş, cinsiyet, başvuru semptomları ve disfonksiyonun türü açısından değerlendirmek ve disfonksiyonun görülme sıklığı ve farkındalığının incelenmesidir.

Metot: Mevcut incelemeye Ekim 2019 - Mart 2020 tarihleri arasında Atatürk Üniversitesi Diş Hekimliği Fakültesi Ağız, Diş ve Çene Hastalıkları Cerrahisi Anabilim Dalına başvuran 18-61 yaş aralığındaki sistemik rahatsızlığı olmayan hastalar dahil edilmiştir (ASA1 ve ASA2).

Bulgular: TME disfonksiyonu olan hastalar genellikle 18-25 yaş aralığındaydı ve bu hastaların çoğunluğu kadınlardan oluşmaktaydı $(p<0.05)$. Bunlar içinde en fazla görülen semptom cinsiyete göre sırasıyla erkeklerde eklem ağrısı, kadınlarda ise hipermobiliteydi $(p<0.05)$. Her iki cinsiyette de bu semptomları sırasıyla eklem sesleri ve kas ağrıları izledi.

Sonuç: Bu çalışmanın sonuçlarına göre TME disfonksiyonun başlıca semptomu genç ve yetişkin kadınlarda ortaya çıkan hipermobilite olarak gözükmektedir. Ayrıca bu çalışmanın sonuçları, Doğu Anadolu Bölgesindeki toplumun TME disfonksiyonu farkındalığınının yetersiz olduğunu göstermektedir.

Anahtar Kelimeler: Hipermobilite, Sıklık, Temporomandibular Eklem Disfonksiyonu

\section{SUMMARY}

Aim: The aim of this study is to evaluate the patients admitted to our clinic from the Eastern Anatolia Region with temporomandibular joint (TMJ) disease in terms of age, gender, symptoms at presentation and the type of dysfunction, and to examine the prevalence and awareness of dysfunction.

Method: Patients with no systemic illness between the ages of 18-61 who applied to Atatürk University Faculty of Dentistry Department of Oral and Maxillofacial Surgery between October 2019 and March 2020 were included in the present study (ASA1 and ASA2).

Results: Patients with TMJ dysfunction were generally between the ages of $18-25$, and the majority of these patients were women $(p<0.05)$. The most common symptoms among these were joint pain in males and hypermobility in females, respectively, according to gender $(p<0.05)$. These symptoms were followed by joint sounds and muscle pain in both sexes, respectively.

Conclusion: According to the results of this study, the main symptom of TMJ dysfunction appears to be hypermobility in young and adult women. In addition, the results of this study show that the awareness of TMJ dysfunction in the people in the Eastern Anatolia Region is insufficient.

Keywords: Hypermobility, Frequency, Temporomandibular Joint Dysfunction 


\section{GİRİŞ}

Temporomandibular eklem (TME), normal ağız işlevi için kritiktir ve bu nedenle çiğneme, yutma, konuşma, ağız sağlığı ve beslenmede rol oynar. TME, menteşe ve kayma hareketlerine izin veren bir eklem diski içeren sinovyal bir eklemdir. Eklem yüzeyleri, yüksek rejeneratif kapasiteye sahip avasküler ve innerve olmayan fibrokartilaj ile kaplıdır. Temporalis ve masseter kasları eklemin hareketini kontrol eder. ${ }^{1,2}$

TME disfonksiyon terimi, kas-iskelet bozukluklarının bir alt sınıflandırmasını ve daha spesifik olarak çiğneme kaslarını, TME'yi ve ilgili yapıları içeren bir dizi belirti ve semptomu temsil eden kolektif bir terimdir. Yetişkinlerin yaklaşık üçte birinin TME disfonksiyon semptomlarına sahip olduğu tahmin edilmektedir. TME disfonksiyonu stres, yaş, cinsiyet, kişilik ve diğer sistematik faktörlerle ilişkilendirilmiştir. ${ }^{1,2}$

Toplumda en çok karşılaşılan sağlık problemlerinden biri de TME disfonksiyonlarıdır. Toplumun neredeyse yarısı en az bir semptoma sahiptir. Bu semptomlar genelde çene eklem ağrıları, kas ağrıları şeklinde gözükmektedir.1,2 TME disfonksiyonu bulunan hastalarda majör semptomlar; kulak ve baş bölgesinde ağrı, kas ve eklem ağrısı, eklem hareket yönünde değişiklik ve eklem sesleridir. 1,3,4 Yapılan araştırmalara bakıldığında bu belirtiler sıklıkla genç kadınlarda gözlenir. ${ }^{1,3}$ TME disfonksiyonun semptomlarını belirlemedeki asıl zorluk çevre komşuluğunda bulunan anatomik yapıların ve dokuların semptomlarının da fazla olmasından kaynaklanmaktadır. TME disfonksiyonun net olarak sıralanmış teşhis kriterleri ortaya konamamıştır ve ortaya konan epidemiyolojik çalışmaların eksikliği sebebiyle bu semptomların dağılımı hakkında mevcut kaynaklarda birbiriyle uyuşmayan görüşler mevcuttur. 5,6 Bu araştırmanın amacı Doğu Anadolu Bölgesinden kliniğimize başvuran hastaları yaş, cinsiyet, başvuru semptom ve disfonksiyonun türü açısından değerlendirmek ve disfonksiyonun görülme sıklığı ve farkındalığının incelenmesidir.

\section{MATERYAL VE METOD}

Bu araştırmamıza Ekim 2019-Mart 2020 tarihleri arasında Atatürk Üniversitesi Diş Hekimliği Fakültesi Ağız, Diş ve Çene Cerrahisi Anabilim Dalına başvuran 18-60 yaş aralığındaki sistemik rahatsızlığı olmayan hastalar dahil edilmiştir (ASA1 ve ASA2).

Hasta muayeneleri tek bir hekim tarafından yapılmıştır. Yapılan muayeneler çift taraflı eklem muayenesi, baş ve boyun muayenesi şeklindedir. Değerlendirmeler 300 hasta üzerinde yapıldı. Hastalar incelenirken aşağıdaki kriterler kayıt altına alınmıştır.

* Cinsiyet : Hastalar kadın ve erkek olarak iki gruba ayrılmıştır.

* Yaş : Hastalar; 18- 25, 26-38 ve 38 yaş üzeri bireyler olarak 3 yaş grubuna ayrılarak sınıflandırılmıştır.

* Başvuru semptomları : Eklem ağrısı, eklem sesleri (klik veya krepitasyon), ağız açma kısıtlıığı (hipomobilite, 20 mm'ye kadar), hipermobilite (35 mm'den fazla), bruksizm (diş gıcırdatması), kulak çınlaması, baş ağrısı vb. subjektif semptomlar, diğer (diş ağrısı, rutin kontrol vb.) olmak üzere sınıflandırılmıştır.

* Disfonksiyonun çeşidi : Hastalardan tanı için gerekli görüldüğünde ortopantomografi ve lateral eklem film görüntüleri alınmıştır ve bu görüntülerden yararlanılmıştır. Yapılan araştırmalarda birçok disfonksiyon sınıflaması mevcuttur. Yaptığımız bu çalışmada biz Okeson'un TME disfonksiyon sınıflamasını ${ }^{7}$ kullanmayı tercih ettik.

Okeson'un sınıflandırmasında kas problemleri, redüksiyonlu ve redüksiyonsuz disk deplasmanları, hipermobilite, hipomobilite ve gelişimsel eklem hastalıkları bulunmaktadır.

Hastaların başvuru semptomları sınıflandırılarak TME disfonksiyon tanısı olan hastalar seçildi ve bu hastalar yaş ve cinsiyetlerine göre ayrı ayrı gruplandırıldı. Hastalara hipermobilite ve hipomobilite teşhisi, lateral eklem filmleri ile birlikte klinik muayene yapılarak konuldu. Hastaların farkındalığını ölçmek için ise hastaların kliniğimize direkt mi başvurduğu yoksa başka bir klinikten mi sevk edildiği soruldu.

\section{BULGULAR}

Yaptığımız çalışmada yaşları 18 ile 60 arasında olan 160 kadın (\% 53.33), 140 erkek (\%46.67) toplam 300 hasta değerlendirilmiştir. Çalışmamızda hastaların $\%$ 26.67'si 18-25 yaş aralığındayken; çoğunluk olan \%43.33'lük kısmı 38 yaş üzeri hastalardan oluşmaktaydı. Hastaların yaş ve cinsiyete göre dağııımları Tablo 1 'de sunulmuştur.

Hastaların başvuru şikayetlerinin cinsiyete göre dağılımı Tablo 2'de sunulmuştur. Çalışmamızda toplam semptomların görülme sıklığı, kadınlarla (\% 57.3) erkekler (\% 42.7) kıyaslandığında sonucun anlamlı olduğu anlaşılmaktadır ( $p<0.05)$. Eklem disfonksiyon 
türüne göre bakıldığında en majör semptom erkeklerde $(n=25)$ eklem ağrısıydı, kadınlarda $(n=40)$ ise eklem hipermobilitesiydi ( $p<0.05$ ). Bununla birlikte kadın ve erkeklerde eklem sesleri ile kulak çınlaması, baş ağrısı vb. subjektif semptomların ve bruksizm sayısının birbirine oldukça yakın olduğu tespit edildi. Hastalarda hipermobilite teşhisi lateral eklem filmleri alınarak ve klinik muayene sonucu konmuştur. (Resim 1)

Tablo 1. Hastaların yaş ve cinsiyet gruplarına göre dağılımı

\begin{tabular}{|l|l|l|l|l|l|l|}
\hline YAŞ & \multicolumn{2}{|l|}{ KADIN } & \multicolumn{2}{l|}{ ERKEK } & \multicolumn{2}{l|}{ TOPLAM } \\
GRUPLARI & $\mathrm{n}$ & $\%$ & $\mathrm{n}$ & $\%$ & $\mathrm{n}$ & $\%$ \\
\hline $18-25$ & 40 & 50.0 & 40 & 50.0 & 80 & 26,67 \\
$26-38$ & 50 & 55.56 & 40 & 44.44 & 90 & 30 \\
N $>38$ & 70 & 53.85 & 60 & 46.15 & 130 & 43.33 \\
TOPLAM & 160 & 53.33 & 140 & 46.67 & 300 & 100.0 \\
\hline
\end{tabular}

Tablo 2. Hastaların kliniğimize başvurduğu zamanki şikayetlerinin cinsiyete göre dağılımı

\begin{tabular}{|l|c|c|c|}
\hline Başvuru şikayeti & Kadın(n)(\%) & Erkek(n)(\%) & Toplam (n) (\%) \\
\hline Eklem ağrısı & $30(54.55)$ & $25(45.45)$ & $55(15.15)$ \\
Eklem sesleri (klik veya krepitasyon) & $10(66.67)$ & $5(33.33)$ & $15(4.13)$ \\
Ağız kısıtllığı (hipomobilite) & $5(62.5)$ & $3(37.5)$ & $8(2,2)$ \\
hipermobilite & $40(66.67)$ & $20(33.33)$ & $60(16.53)$ \\
Bruksizm & $8(57.14)$ & $6(42.86)$ & $14(3.86)$ \\
(diş gıcırdatması) & & & \\
Kulak çınlaması,baş ağrısı vb. & $15(55.56)$ & $12(44.44)$ & $27(7.44)$ \\
sübjektif semptomlar & & & \\
Diğer (diş ağrısı,rutin kontrol vb.) & $100(54.35)$ & $84(45.65)$ & $184(50,69)$ \\
toplam & $208(57.3)$ & $155(42.7)$ & $363(100.0)$ \\
\hline
\end{tabular}

*Hastaların birçoğunda birden fazla semptomun berababer görüldüğü tespit edildi.
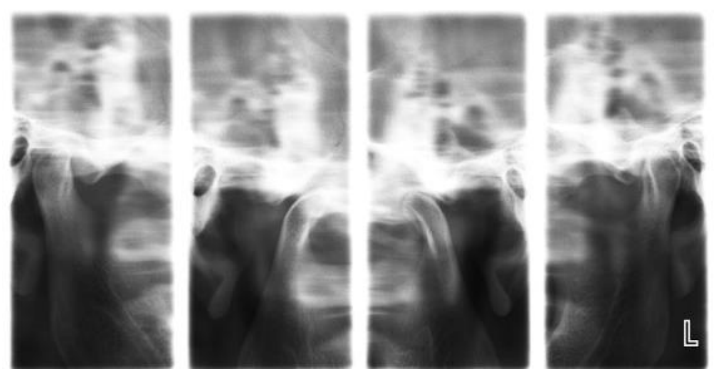

Resim 1. Hipermobilite teşhisi konan bir hastanın lateral eklem filmi

Çalışmamızda elde ettiğimiz verilere göre TME disfonksiyonlarının büyük çoğunluğunu hipermobilite (\%39.47) oluşturuyordu. Bu veriyi sırasıyla redüksiyonsuz disk deplasmanı + kas problemleri (\%13.16), tek başına kas problemleri (\%13.16) ve redüksiyonlu disk deplasmanı + kas problemleri (\%10.53) takip ediyordu. (Tablo 3)

Çalışmamızda ayrıca Doğu Anadolu Bölgesindeki hastaların farkındalığını ölçmek için bu 300 hasta arasından başka servislerden (KBB ve Noroloji) kliniğimize gelen hasta sayısına bakıldı. Başka servislerden kliniğimize yönlendirilen $42(\% 70.0)$ si kadın ve 18 (\%30.0) i erkek olmak üzere 60 hasta mevcuttu.
(Tablo 4) Bu 60 hasta araştırmaya katılan bütün hastaların \%20 'siydi.

Tablo 3. Hastada tepsit edilen disfonksiyon çeşidinin cinsiyete göre dağılımı

\begin{tabular}{|l|c|c|c|}
\hline Disfonksiyon Çeşidi & Kadın (n) (\%) & Erkek (n) (\%) & Toplam (n) (\%) \\
\hline Hipermobilite & $40(66.67)$ & $20(33.33)$ & $60(39.47)$ \\
\hline Hipomobilite & $5(62.5)$ & $3(37.5)$ & $8(5.26)$ \\
\hline Kas Problemleri & $12(60.0)$ & $8(40.0)$ & $20(13.16)$ \\
\hline $\begin{array}{l}\text { Redüksiyonlu Disk } \\
\text { Deplasmanı }\end{array}$ & $8(66.67)$ & $4(33.3)$ & $12(7,89)$ \\
\hline $\begin{array}{l}\text { Redüksiyonlu Disk } \\
\text { Deplasmanı } \\
\text { Problemleri }\end{array}$ & $10(62.5)$ & $6(37.5)$ & $16(10.53)$ \\
\hline $\begin{array}{l}\text { Redüksiyonsuz Disk } \\
\text { Deplasmanı }\end{array}$ & $12(75.0)$ & $4(25.0)$ & $16(10.53)$ \\
\hline $\begin{array}{l}\text { Redüksiyonsuz Disk } \\
\text { Deplasmanı } \\
\text { Problemleri }\end{array}$ & $14(70.0)$ & $6(30.0)$ & $20(13.16)$ \\
\hline Toplam & $101(66.45)$ & $51(33.55)$ & $152(100.0)$ \\
\hline
\end{tabular}

Tablo 4. Başka servislerden kliniğimize sevk edilen hasta sayısının cinsiyete göre dağılımı

\begin{tabular}{|l|l|l|l|}
\hline Yönlendirilen Servisler & Kadın (n) (\%) & Erkek (n) $(\%)$ & Toplam (n) (\%) \\
\hline KBB (Kulak Burun ve Boğaz) & $30(75.0)$ & $10(25.0)$ & $40(66.67)$ \\
\hline NÖROLOJİ & $12(60.0)$ & $8(40.0)$ & $20(33.33)$ \\
\hline Toplam & $42(70.0)$ & $18(30.0)$ & $60(100.0)$ \\
\hline
\end{tabular}

\section{Ístatistiksel Analiz}

Analiz için değişkenlerimiz yaş, cinsiyet, eklem sesleri varlığı, ağız açıklığı aralığıydı. Normal dağımayan değişkenleri karşılaştırmak için Kruskal-Wallis ve Mann-Whitney U testleri kullanıldı.

Anonim veriler üzerinde IBM SPSS 20 kullanılarak analiz yapıldı. Veri dağılımını belirlemek için Kolmogorov-Smirnov ve Shapiro-Wilk normallik testleri kullanıldı. İstatistiksel anlamlıık düzeyi $p<0.05$, Güven aralığı\% 95'ti.

\section{TARTIŞMA}

Orofasial hastalıklar çok yaygın görülmekle birlikte bu hastalıkların bir alt grubu da TME disfonksiyonlarıdır. TME disfonksiyonlarından herhangi birine sahip olan hastalar günlük işlerini yaparken, konuşurken, yemek yerken çok ağrı çekebilmektedir. Bizim yaptığımı çalışma sonucunda TME disfonksiyonu şikayetiyle başvuran hastaların daha çok kadınlardan oluştuğu gözlemlendi. Godoy ve arkadaşları ${ }^{8}$ Brezilya'daki gençlerde yaptıkları çalışmada TME disfonksiyonlarında cinsiyetin çok önemli bir yer tuttuğunu söylemişlerdir. Bununla birlikte TME disfonksiyonlarında cinsiyetin dental kaynaklardan bile önce gelebileceğini

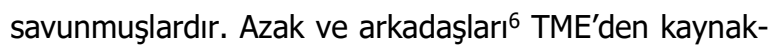
lanan hastalıkların bulgularının sıklığı üzerine yaptıkları araştırmada bazı bulguların kadın- larda erkeklere göre oldukça yüksek olduğunu bulmuş- lardır. Manfredini ve 
arkadaşlarının $^{1}$ TME disfonksiyonu tanılı hastalar üzerinde yaptıkları araştırmada mevcut hastaların \%73.2' sini kadınlar oluşturmaktadır. Bu çalışmalara güzel bir örnek, Winocour ve arkadaşlarının ${ }^{9}$ yaptığı çalışmada ergenlik dönemindeki kadınların yine aynı yaş grubundaki erkeklere oranla daha fazla TME rahatsızlığına sahip olduğunu gösterdikleri çalışmadır. Yazarlar bu TME rahatsızıklarının kadınlarda daha fazla gözükmesinde hormonal metabolizmanın ve yüksek eklem laksitenin (gevşeklik) etkili olduğu düşünülmektedir. ${ }^{10}$ Yapılan çalışmalarda yüksek laksitenin sebebi, östrojen reseptörlerinin eklem ligamentlerinin metabolik fonksiyonları üzerine yaptığı önemli destekleyici etkiler olarak anlatılmaktadır. ${ }^{10}$ Schmitter ve arkadaşları ${ }^{10}$ belli bir yaşın üstündeki hastaların \%38'inde eklem seslerinin var olduğunu; genç birey- lerde eklem ağrı oranlarının yaşlılardan daha fazla olduğunu bulmuşlardır. Levitt ve McKinney'in ${ }^{11}$ tam 10.000 TME disfonksiyonu tanısı konmuş hasta üzerinde yaptıkları çok kapsamlı bir araştırmada genç bireylerdeki belirti verme sıklığı ve şiddetinin diğer gruplara oranla fazla olduğunu bulmuşlardır. Bizim çalışmamızda ise yine bu durumu destekleyici bazı sonuçlar elde edilmiştir. Genç bireylerde TME disfonksiyonuna çok rastlanmasının sebebi, bu bireylerin yaşlı bireylere oranla daha fazla farkındalıklarının olması ve yaşı bireylerin tam tersine buna çok fazla özen gösterme- mesi olabilir. Bu çalışmalar; TME disfonksiyonlarının genç bireylerde daha fazla ortaya çıkması ile yaşa bağlı bir korelasyon olduğu sonucunu ortaya koyacaktır.

Mevcut çalışmada kliniğimize eklem ağrısı ile başvuranların oranı yüksek bulundu ve bu sonuçlar Ozan ve arkadaşlarının ${ }^{5}$ yaptığı çalışmadaki sonuçları ile örtüşmektedir. Yine Ozan ve arkadaşlarının ${ }^{5}$ yaptığı çalışma ile benzer olarak eklem ağrısı ile başvuranların oranı kadınlarda erkeklerden daha fazla bulundu. Bununla beraber, Jagger ve Wood $^{12}$ Arap ırkı üzerinde yaptıkları çalışmada major semptom olarak eklem seslerinin olduğunu bildirmişlerdir. List ve Dworkin ${ }^{13}$ İsveç halkı üzerinde yaptıkları araştırmada redüksiyonlu ve redüksiyonsuz disk deplasmanlarının yüzdesini sağ ve sol eklemlerde ayrı ayrı olarak $\% 32.0$ ve $\% 39.0$ olarak bildirmişlerdir. Tozoğlu ve ark. ${ }^{14}$ yaptığı çalışmada ise disk deplasmanlarına ek olarak kas problemleri belirgin olarak görülmektedir ve bu majör semptomun ağrı olarak bulgu vermesinin kassal etkilerden meydana geldiğini bildirmişlerdir. Ayalı ve Ramoğlu'nun ${ }^{15}$ diş hekimliği öğrencileri üzerinde yaptıkları çalışmada ankete katılan tüm bireylerin TME disfonksiyonu sıkığının \%56.5 olduğunu ve kadınlarda bu oranın da- ha çok olduğunu bildirmişlerdir. Eroğlu ve ark ${ }^{16}$ yaptığı çalışmada ise TME, baş-boyun, yüz-kulak bölgesi ağrılarının görülme sıklığını araştırmışlar ve hastaların \% 23.5'inde eklem bölgesinde ağrı olduğunu bildirmişlerdir.

Uzun yıllar temporomandibular disfonksiyonu ile ilgili birçok sınıflama uygulamaya konulmuştur. Bell ${ }^{17}$ tarafından geliştirilen ve Amerikan Diş Hekimleri Birliği18 tarafından güncellenerek yapılan sınıflama, Okeson ${ }^{7}$ tarafından bir kez daha modifiye edilerek günümüzde yaygın olarak kullanılmaktadır. Bu sınıflandırma ile TME disfonksiyonu; çiğneme kası rahatsızIıkları, TME düzensizlikleri, kronik mandibular hipomobilite ve gelişimsel rahatsızlıklar olarak dört ana başlık altında toplanmıştır. Bu sınıflamada çiğneme kası rahatsızlıkları, TME düzensizlikleri, kronik mandibular hipomobilite ve gelişimsel rahatsızlıkları şeklinde bölümler olduğundan dolayı bu sınıflama TME disfonksiyonu hakkında ayrıntılı bilgi içerir. Bu sebeple makalemizde Okeson'un modifiye sınıflamasını tercih ettik.

Bizim yaptığımız çalışma da bu bulguları destekler niteliktedir. Çalışmamızda toplam semptomların görülme sıklığı cinsiyete göre kıyaslandığında kadınlarda daha fazlaydı. Eklem disfonksiyon türüne göre bakıldığında ise en majör semptom erkeklerde eklem ağrısı (\%45.45), kadınlarda ise eklem hipermobilitesiydi (\%66.67). Doğu Anadolu Bölgesindeki kadınlarda hipermobilite oranının yüksek olması bu çalışmanın diğer çalışmalardan farklı bir verisidir. Hipermobilite oranının fazla olmasının nedeni bölgesel yapının etkisi ve beslenme alışkanlığı gibi etmenler olabilir. Başka bir sebebi ise genç kadınlardaki TME rahatsızlıklarının daha fazla gözükmesinde hormonal metabolizmanın ve yüksek eklem laksitenin (gevşeklik) etkili olduğu bildirilmektedir. ${ }^{10}$

\section{SONUÇLAR}

$\checkmark$ Kliniğe başvuran hastalarda; TME disfonksiyonu tanısı konan hastaların çoğunluğunu genç ve yetişkin kadınlardı.

$\checkmark$ TME disfonksiyonu tanısı konan hastaların yaş aralığı çoğunlukla 20-40 yaş arasındaki kadınlardı.

$\checkmark$ Eklem disfonksiyon türüne göre bakıldığında, en majör semptom erkeklerde eklem ağrısı, kadınlarda ise eklem hipermobilitesiydi.

$\checkmark$ KBB'den veya nörolojiden kliniğimize sevk edilen 40 hastanın olması (TME disfonksiyon tanısını bu kliniklerde alan) Doğu Anadolu Bölgesindeki toplumun TME disfonksiyonu farkındalığı konusunda yetersiz olduğunu göstermektedir. 
Finansal Destek

Yazarlar bu çalışma için finansal destek almadıklarını beyan etmişlerdir.

Çıkar Çatışması

Yazarlar çıkar çatışması bildirmemişlerdir.

\section{KAYNAKLAR}

1. Manfredini D, Chiappe G, Bosco M. Research diagnostic criteria for temporomandibular disorders (RDC/TMD) axis I diagnoses in an Italian patient population. J Oral Rehabil 2006;33:551-8.

2. Nassif NJ, Al-Salleeh F, Al-Admawi M. The prevalence and treatment needs of symptoms and signs of temporomandibular disorders among young adult males. J Oral Rehabil 2003;30:94450.

3. Onder $M E$, Tüz HH, Koçyiğit $D$, Kişnişci RS. Longterm results of arthrocentesis in degenerative temporomandibular disorders. Oral Surg Oral Med Oral Pathol Oral Radiol Endod 2009;107:e1-5.

4. Guarda-Nardini L, Manfredini D, Ferronato G. Total temporomandibular joint replacement: a clinical case with a proposal for post-surgical rehabilitation. J Craniomaxillofac Surg 2008; 36:403-9.

5. Ozan F, Polat S, Kara I, Küçük D, Polat HB. Prevalence study of signs and symptoms of temporomandibular disorders in a Turkish population. J Contemp Dent Pract 2007;8:35-42.

6. Nekora-Azak A, Evlioglu G, Ordulu M, Issever $H$. Prevalence of symptoms associated with temporomandibular disorders in a Turkish population. J Oral Rehabil 2006;33:81-4.

7. Okeson JP. Management of Temporomandibular Disorders and Occlusion. 2003, 5th edition, Mosby. 191-245.

8. Godoy F, Rosenblatt A, Godoy-Bezerra J. Temporomandibular disorders and associated factors in Brazilian teenagers: a cross-sectional study. Int J Prosthodont 2007;20:599-604.

9. Winocur E, Littner D, Adams I, Gavish A. Oral habits and their association with signs and symptoms of temporomandibular disorders in adolescents: a gender comparison. Oral Surg Oral Med Oral Pathol Oral Radiol Endod 2006;102:482-7.

10. Schmitter $M$, Rammelsberg $P$, Hassel A.The prevalence of signs and symptoms of temporomandibular disorders in very old subjects. J Oral Rehabil 2005;32:467-73.

11. Levitt SR, McKinney MW. Validating the TMJ scale in a national sample of 10,000 patients: demographic and epidemiologic characteristics. J Orofac Pain 1994;8:25-35.
12. Jagger RG, Wood C. Signs and symptoms of temporomandibular joint dysfunction in a Saudi Arabian population. J Oral Rehabil 1992;19:353- 9.

13. List T, Dworkin SF. Comparing TMD diagnoses and clinical findings at Swedish and US TMD centers using research diagnostic criteria for temporomandibular disorders. J Orofac Pain 1996;10(3):240-53.

14. Tozoğlu S, Yavuz MS, Büyükkurt $M C$, Dayı $E$, Miloğlu Ö, Savaş Z. Erzurum ve çevresinden TME rahatsızlığı nedeniyle kliniğimize başvuran hastaların retrospektif incelenmesi. Atatürk Üniv Diş Hek Fak Derg 2008, 18:90-3.

15.Ayalı A, Ramoğlu S. Kuzey Kıbrıs'ta Diş Hekimliği Fakültesi Eğitiminde Temporomandibular Eklem Disfonksiyonunun Prevalansı ve Şiddetinin Araştırılması. Atatürk Üniv Diş Hek Fak Derg 2014; 24: 367-72.

16. Eroğlu, C, Keskin Tunç, S, Elasan, S. Yönetim Dönemde ve Öncesinde Temporomandibular Eklem, Baş-Boyun, Yüz-Kulak Bölgesi Ağrılarının Görülme Sıklığının Araştırılması: Pilot Çalışma. Atatürk Üniv Diş Hek Fak 2018; 28: 157-61.

17. Bell WE. Temporomandibular Disorders, 2th ed. Chicago, Year Book Medical Publishers, 1986.

18. Griffiths RH. Report of the president's conference on the examination, diagnosis andmanagement of temporomandibular disorders. Journal of the American Dental Association, 1983, 106: 75-7.

\section{Sorumlu Yazarın Yazışma Adresi}

Yunus Emre AŞÇI

Department of Oral and Maxillofacial Surgery, Ataturk University Faculty of Dentistry e-mail: yunusemreasci1907@outlook.com 